\title{
Do studies of the nature of cases mislead about the reality of cases? A response to Pattison et al
}

\author{
Roger Higgs King's College, London
}

\begin{abstract}
This article questions whether many are misled by current case studies. Three broad types of style of case study are described. A stark style, based on medical case studies, a fictionalised style in reaction, and a personal statement made in discussion groups by an original protagonist. Only the second type fits

Pattison's category. ${ }^{1}$ Language remains an important issue, but to be examined as the case is lived in discussion rather than as a potentially reductionist study of the case as text.
\end{abstract}

(Fournal of Medical Ethics 1999;25:47-50)

Keywords: Case ethics; methods in ethics education; problem-based learning; literature; narrative

Discussion of cases is a key part of teaching and learning in medical ethics. So questions raised about the nature of cases (in the sense of the form in which they are presented) and about how this nature may alter learning or analytic outcome are important to answer. Since the educational process in applied ethics is usually at one remove from the real-life problem area it examines, an element of unreality is inevitable. But how great an element is acceptable or desirable? Pattison et al believe they see in the format of ethics cases a deliberate artifice which may mislead, and perhaps at some level is intended to do so. If this is true, not only should discussants be alert to it, they should also be able to make allowances for it and correct for it, like riding a bicycle with the handlebars askew: they might even ask about the morality of it. Pattison's article suggests the background to such bias, and offers a way to approach such cases, which is drawn from literary criticism. The discussant, it seems, is no longer dealing with simply reported fact, but a subtle combination of fact and fiction. "Faction", as this is sometimes called, already suggests the purposive and poten- tially polemical nature of such constructions. Caveat lector.

\section{Case in reality}

What is the reality of this assertion? How often do we find this happening, and in what sorts of ways or situations? The authors suggest that such cases should be seen as literary text, a "woven" form of words which goes beyond mere statement or report. We assume, given the plethora of examples available, that they would show how this happens; even if not, in limited space, how often. That they do not should not put us off but as they themselves suggest should alert us to what has been left out. The answer is of course available elsewhere. Most textbooks of medical ethics quote cases to illustrate the moral points made in the book, ${ }^{2}$ and some do so as the main way of driving the argument forward. ${ }^{3}$ Some books have been created almost entirely out of case material. ${ }^{4}$ The Fournal of Medical Ethics has published cases as Case conferences and At the coalface: medical ethics in practice. Case material in teaching projects may be more difficult to reference, but a similar pattern is found, as is suggested: some cases may be offered to capture the attention, but some are the direct substrate of the teaching. But when teaching follows the format of small group learning, case discussion is almost inevitable and the cases then presented are probably the "originals" of much of the printed material.

So we see there is probably a spectrum of case types. Some cases are offered in dry medical fashion, or in harmony with cases from legal text: "JR was a 54-year-old male, presenting to the doctor with chest pain". Some are set out in much more of a readable and interactive format: "John $\mathrm{R}$ was very anxious when he first got chest pain, as his Dad had died when he was about that age; so he wasted no time in going down to see his doctor to get it sorted out". The third type, usually 
Teaching medical ethics: Do studies of the nature of cases mislead about the reality of cases? A response to Pattiso et al

presented personally in case discussions by a participant asked to offer material for discussion, would go differently: "Yes, I'd like to present a case from yesterday's clinic. Mr R is a middle-aged man-just about the same age as me, actuallywho came in with what seemed to be a minor episode of an ache in the chest but which he presented with such great agitation that he made me feel anxious too." Three basic types may be too few. No doubt different sorts of examples could be presented with almost infinite variation. But this triptych serves its primitive purpose in giving some real text for us to work on. (Readers who are looking for the ethical content will have to read on in their imagination.)

\section{The case accusative?}

In the first example ("JR"), we do seem a long way from literature, even if it is undeniably read as text in its sense of written material. But what this thin sort of piece does, by revealing its underlying skeletal structure, as it were, is to recall its origins. These lie not in literature but in medicine, or perhaps in law. Health care ethics achieved its current effective position in professional education by starting where professionals were; that is, thinking about real cases. Although much medical progress is now made in the laboratory and a long way from the sick, this has only relatively recently been so. For years advances in medicine and nursing were made by describing how patients suffered as a rationale for treatment (however misguided). The realities of the categories thus created-illnesses, diseases, syndromes - can be challenged, and there is a whole literature on "disease as social construct". But constructed they were (and are) as cases, in a formalised (or even formalinised) fashion, to test whether they fitted in allopathic medicine a generalisable and therefore a potentially diagnosable and even treatable shape. "Caseness" has re-emerged in areas like psychiatry to determine, for instance the difference between someone depressed and someone sad (or in love). This process creates something stark and cold: it is hard to recognise the person in it. "Am I really like that?" said one of my patients reading his hospital discharge summary. The young Wilfred Owen spelt it out in a letter home to his mother from the parish near Reading two years before the outbreak of war: " . . a gentle little girl of five, fast sinking under Consumptioncontracted after chicken pox. Isn't it pitiable . . . This, I suppose is only a typical case: one of so many Cases! O hard word! How it savours of rigid frigid professionalism! How it suggests smooth and polished, formal, labelled, mechanical callousness!" Owen may have been privately creating literature, but what he described was an affront, an injustice, possibly even in his eyes an evil, not just in the reality of the death of the chil $\bar{\phi}$ but the way in which doctors would (an probably did) describe her. Yes, from the Pattiso checklist in the medical case something has beeof left out, for sure, but it is actually the range an $\$$ wealth of emotional responses and relationship which we should want there in normal descriptivg speech. If a mother described her child in the manner of Owen's doctor, we should worry aboug her psychological state. So perhaps we are right to worry about medical ethics cases presented lik this: but not because they are full of literary artion fice.

\section{The case evocative?}

The second type of presentation ("John R") may" be in reaction to just this type of presentation. Im the stark "JR" type we see professional simplifica? tion at work, and we are familiar with it. A patients we describe what bothers us to our general practitioner (GP), and if a referral is needed she frames it in a certain way for the specialist to read. We may have tested our story with a friend before we even got to the GP, and had subtly altered. Symptoms could likewise be see as language either understood or misinterpretef by their "owner" (interestingly, this is a concepf which seems to have been adopted by literar criticism in phrases like "symptomatic places" At each stage someone takes a view. There is nof "view from nowhere". ${ }^{7}$ In this sense, health care reality is reality; but it bothers us. No one who thinks for more than a second is deceived. Tho case diminishes the person, as indeed it intended to, just as the green towels on the opero ating table hide the human figure. Here is a time for objectivity and a focus on the body alone. But without being able subsequently to change out distance and involvement, to move the power of the microscope, as it were, in our way of relating thinking and describing, we are stuck in a distant and uninvolved view of other people which medi0 cal ethics can hardly condone. Something has to be done to remind professionals about the person beyond the case. There are all sorts of techniques: One of them is to "write up" the style and creat the "thick" case. There are dangers here too. We release more highly charged words and sugges $\bar{\phi}$ feelings which may muddy or stir up the water. may be like dangerous rafting. So we avoid th $\overrightarrow{8}$ Charybdis of callousness only to get sucked inte the Scylla of false artifice.

Or do we? Some authors of case booke acknowledge that a fictional process has gone ons. "Story" is a word often used in describing this sor of style. "However fictional they may be in their 
particulars, these cases are intended to raise the kinds of ethical dilemmas we confront in the real world of medical practice and research" reads the introduction to one of the best known series of case studies. ${ }^{9}$ Why should this change of style be necessary? We may acknowledge one reason, the attempt to engage our "limited sympathies", which Geoffrey Warnock so aptly described as "the object of morality". ${ }^{10}$ Another reason is "the familiar issue of confidentiality" which perhaps should not be dismissed so lightly. There are many players in the drama, but it is clear that many of the important issues arise from lack of sympathy between them, especially a misunderstanding between professional and patient. A counsel of perfection here would certainly be to engage the patient or relative in constructing the story. We did this in the case of the elderly cricketer who preferred death to losing his leg. ${ }^{11}$ His brave relatives in their bereavement were so struck by what they had seen happening that they were prepared to debate with a (surrogate) surgeon in front of a hundred or so medical students. Apart from excellent debate and interesting ethics, it was moving and apparently extraordinarily therapeutic: from being angry and distressed the relatives changed, within the framework of the teaching session, to being close to understanding what the surgeon was trying to achieve and why he acted as he did. It was a powerful and empowering experience for all present: but one that sadly did not include the actual surgeon. We have to accept that real-life ethical conflicts are very hard, in our present Western society, to debate or thrash out in person. There is too much of the adversarial, the political, the defensive in the conduct of Western health care to allow it. "I'm sorry, I made a mistake" is hard enough to say across a pillow in bed, let alone across a consulting room. Certainly it requires special people and special structures to spell out and then discuss in modern health care. We know that we need to move towards open and personal debate, for all the arguments advanced in Pattison, and more. But meanwhile, in order to allow cases to come to light and be discussed, we do still need the protection of a fictionalising process which prevents a person saying: (as one reader angrily proclaimed to Louis de Bernière after reading Captain Corelli's Mandolin) "You have written my life story here".

\section{Case conferences}

The method used in case conferences in this journal in the past is simple to explain. A real case was "passed across" a similar family, group or situation (also from real life) and the details were merged or exchanged. The family was real, the case real, but not in that family, for instance. On one occasion when this was not done, the result was dramatic. I looked after a woman who was dying of breast cancer and wanted me to take her life. It was deeply disturbing to both of us, not least because we had been patient and doctor for a long time and we were also friends. I wore the sweaters she knitted me. My initial refusal to help cut her to the quick. I then offered to maintain supplies of analgesic so that she could take her own life. She did not need them in the end. I wrote up the case anonymously but just as it felt and seemed to me. ${ }^{12}$ I was contacted at once because a specialist advisor to the journal had challenged the reality of the case. It was pure fiction, he said: "No one writes up medical cases like that". (Interestingly enough, he also wrote and published novels in his spare time.)

Why did I write anonymously, and change my elderly friend's name? Perhaps a little to protect her memory. To protect myself from the forces of the law, certainly. As one commentator said, I had, by offering to assist her suicide, risked committing a crime, "albeit an unusual one". I wrote partly to celebrate her challenge and her courage. I knew all too well what some of her perceptions were. But also I wrote because I was still distressed and at the time confused about whether what I had done was right. That one of the commentators "foregrounded" the sweaters revealed much that at that time was not well known to me. One issue was that discussions about euthanasia occur clinically between friends, and usually old friends. However poorly written, I suspect (not very hermeneutically) that this case would be seen as a literary one in the Pattison format. But I doubt that most true authors write even autobiographically out of perplexity, to try to work it out. Some may, like Brian Keenan quoting DH Lawrence, write to "throw up their sickness in books"13- but not in order to examine their reasoning.

\section{The author present and the case tense?}

So we return to the third type ("Mr R") offered by a group member in an ethics session. I am no group analyst, but I attend groups in an educational or support framework almost every week. In medical ethics groups, participants do not usually present cases because they want to show off. Even if they think they were right (as we all tend to do) they want to test out why. They are offering their experience (it seems to me to be often quite bravely) because they didn't know what to do, or still feel unresolved about what they did. Just as in therapeutic groups we forget the moral at our peril, so in ethics discussion groups we should not entirely forget the therapeutic. 
Teaching medical ethics: Do studies of the nature of cases mislead about the reality of cases? A response to Pattiso玄 et al

\section{Language: cherchez $M$ Chauvin}

In the discussion that follows the presentation, there is always challenge. Often it is about the words used, both by the "author" and by others. What sorts of language are being used and what are the implications? This is an important question to ask at any time, but especially in ethics work. We should also ask it of any ethics article. What sort of descriptions of participants' motivations do we find in Pattison? In contrast to the above (admittedly partisan but perhaps more sympathetically edged) approach, we read that practitioners use cases to "demonstrate their own ethical bravado and skill . . . it was hell!" Sensationalist presentations render "the client or service user passive, evil or both while the 'brave, conscientious health workers' make difficult decisions". Disregard of the agents' perceptions is "cavalier". Purposes may be "professional pugilism, voyeurism" and so on. The warnings seem unbalanced. It's not that we haven't all come across awful colleagues, in medicine as well as philosophy and literary criticism, it's just that we have been enjoined to look for the authors' own "biases and prejudices ... and blind spots". So what about cases that they actually refer to? There are none, as we have seen, but the one piece of text that is quoted stops us in our tracks at the second word of the main piece. Alastair MacIntyre is honoured at the head: "man (sic) ..." (We have immediate views about the genre: we are going to analyse the quote. We don't). Never mind, but here is enough suspicion to start our hermeneutics. What does this "sic" mean? That the reader won't have noticed the slanted language, in 1999? We don't all live in Lambeth, I suppose. That women can't tell stories? Stand up on the other one. That Professor MacIntyre is a flawed thinker? I think Jane Austen should be told. In context, MacIntyre is writing with Aristotle at his elbow, reminding him that "man is a political animal". So the "sic" has at least allowed me to see the wit, even if it spoils the cadence and distracts from the almost psalm-like beauty of the antithesis between " a story telling animal" and "a teller of stories that aspire to truth". I dreamt that night of reading Hamlet: "To be (sic) or not (sich) to be (sick)". Then I knew after looking at the article I had really got into "symptomatic places". Of course both MacIntyre and Pattison et al are right. If the task of anthropology is to "make the familiar strange", we know that we should proceed in ethics by making the accepted questionable. But should we focus on text, or what is (haltingly and imperfectly) trying to be described?

\section{Implications}

If ethics discussion, rather than falling into the (medical) trap of reductionism, is to do its jo really well, we need, first and foremost, discussion process that is good, and second, aF opportunity to be both iterative and imaginative Technical criticism and point-scoring could be just another way of not coming to the moral pointes that of engaging our limited sympathies as part $\$$ the object of our moral endeavour. Discussants, readers or analysers have to approach a moras question, placed in the context of a case, not onl from every available direction (in terms of charac ters and content) but also with constantly changer ing moral and personal "distance". On the on $\overrightarrow{\vec{f}^{\prime}}$ hand, we need to be able to stand back; in order to make policy decisions, act for an institution, see the principles clearly or do something that requires courage or fixed purpose. On the othere we need to be able to get closer; to understane

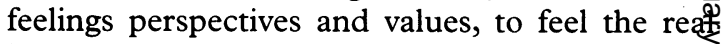
heat of the dilemma, to use our imagination to get ourselves right to the core of the conflict. In all thise a criticism of the literary form of the case may help. But this is knowledge to which we may (and usually do) come by other means, in a well rum

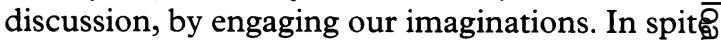
of what they say at Heathrow, I don't think it mato ters much who packs the case, and how: but how it's unpacked and used, that gets us close to realo ity, and to good ethics.

Roger Higgs, MBE, FRCP, FRCGP, is a Genera: Practitioner and Professor of General Practice a King's College, London

\section{References}

1 Pattison S, Dickenson D, Parker $M$ and Heller T. Do caso studies mislead about the nature of reality? fournal of Medica\$ Ethics 1998;24:42-46. 2 Beauchamp TL, Childress JF. Principles of biomedical ethics [4t织
ed]. New York: Oxford University Press, 1994 .

3 Higgs R, Campbell A. In that case: medical ethics in everydaf practice. London: Darton Longman \& Todd, 1982

4 Aickernan TF, Strong C. A casebook of medical ethics. New York Oxford University Press, 1989.

5 Day Lewis C. The collected poems of Wilfred Owen. London Chatto \& Windus, 1977: 16

6 Cuddon JA. Dictionary of literary terms and literary learnin 0

7 Nagel T. The view from nowhere. Oxford: Oxford Universit Press, 1986.

8 See reference 3: 3 .

9 Crigger BJ. Cases in bioethics: selections from the Hastings CenterO Report. New York: St Martin's Press, 1998: xvi.

10 Warnock GJ. The object of morality. In: Ayer AJ, O'Grady J, eds $A$ dictionary of philosophical quotations. Oxford: Blackwell, $1994 \Omega$

11 Higgs R, Livesley B, Rennie J. Earning his heroin but seekingD release while the surgeon advises amputation. Fournal of Medi cal Ethics 1987;13:43-8.

12 Higgs R. Cutting the thread and pulling the wool: a request for euthanasia in general practice. Fournal of Medical Ethics $1983 \AA$ 9:45-9.

13 Keenan B. An evil cradling. London: Vantage, 1992: xiii 